\title{
Desenvolvimento urbano baseado em conhecimento e ecossistemas de inovação urbanos: uma análise em quatro cidades brasileiras
}

Luiz-Marcio Spinosa. Pontifícia Universidade Católica do Paraná, Curitiba, Brasil. Márcia-Regina Krama. Instituto de Pesquisa e Planejamento Urbano de Curitiba, Curitiba, Brasil.

Carlos Hardt. Pontifícia Universidade Católica do Paraná, Curitiba, Brasil.

RESUMO | O esforço em promover políticas públicas e estratégias que favoreçam a inserção de cidades e regiōes na economia do conhecimento tornou-se imperativo. Este trabalho explora as relaçóes entre o Desenvolvimento Urbano Baseado em Conhecimento (DUBC) e os Ecossistemas de Inovação (EI) no meio urbano. A partir de uma pesquisa por triangulação e um modelo conceitual foram analisados quatro ecossistemas de cidades brasileiras. Concluiu-se que: (i) há harmonia entre DUBC e os EI, devido a similaridades conceituais; ii) o DUBC e os EI são manifestaçóes sociotécnicas que ocorrem no meio urbano, havendo intrínseca relação do DUBC com este meio, o que é desejável, mas não obrigatório para os EIs; iii) há convergência de interesses e de atuação dos DUBC e dos EI e ;iv) o DUBC pode influenciar positivamente os resultados e impactos buscados pelos EI. Nestes termos, emergem recomendaçóes para induzir mais facilmente o surgimento de EI.

PALAVRaS-CHAVE | sociedade do conhecimento, inovação tecnológica, desenvolvimento regional.

ABSTRACT | The need to foster public policies and strategies to promote the inclusion of cities and regions in the knowledge economy became permanent. This work specifically explores the relationship between Knowledge Based Urban Development (KBUD) and Innovation Ecosystems (IE). A conceptual model, based on triangulation methods, is proposed and applied in four Brazilian ecosystems. We found that: (i) There are major conceptual similarities between KBUD and IE; (ii) KBUD and IE are sociotechnical events that occur in urban areas, revealing relationships that are intrinsic for the KBUD, and are desirable and not mandatory for the IE; (iii) there is convergence of interests and activities issued from KBUD and IE; and (iv) KBUD development perspectives can positively influence the results and impacts pursued by IE. Recommendations emerge from the combination of these findings, in order to obtain more integrated planning and thus encourage the emergence of IE.

KEYWORDS | knowledge economy, technological innovation, regional development. 


\section{Introdução}

Nas últimas décadas os planejadores urbanos têm se confrontado com o desafio de conciliar a evoluçáo urbana com o surgimento da economia do conhecimento (Clarke, 2001; Drucker, 2011; Powel \& Snellman, 2004; Smith, 2000), cuja origem é atribuída às chamadas sociedade da informação ou sociedade em redes (Castells, 1996, 1997, 1998). A economia do conhecimento advoga a necessidade de geração, difusão e uso do conhecimento nas economias modernas; um fenômeno global que sustenta que conhecimento transformou-se na força motriz para o crescimento econômico e o desenvolvimento social, em grande parte alicerçados na promoçáo de inovaçóes. Conhecimento e inovaçáo estão presentes na agenda dos planos de desenvolvimento dos países, desempenhando papel relevante na geração de riqueza e empregos qualificados (World Bank, 2010). Algumas regióes têm obtido melhores resultados através do reforço e ampliação de políticas científicas, tecnológicas e de inovação que realçam a mobilização dos processos de aquisição e uso de conhecimentos e de capacitaçóes inovadoras como parte integrante e fundamental de suas estratégias de desenvolvimento (Organisation for Economic Co-operation and Development [oECD], 2010).

Assim como vários outros países, o Brasil busca acompanhar este movimento. Políticas públicas têm emergido de forma a conduzir os esforços nacionais (De Negri, Kubota \& Baessa, 2008; Pacheco \& Almeida, 2013), uma vez que há um amplo consenso junto a empresários, governantes e a comunidade científica de que os processos de inovação são diretamente responsáveis por saltos na competitividade e na qualidade do sistema produtivo (Arbix, 2007). De forma nem sempre explícita estas políticas têm promovido o desenvolvimento de Ecossistemas de Inovação (EI).

Os EI constituem lugares privilegiados para a condução da dinâmica de inovação e tornam-se importantes ativos de competitividade entre cidades, regióes e mesmo países. No Brasil tem se destacado a formação de EI a partir de parques tecnológicos inseridos ou próximos ao meio urbano. Segundo pesquisa realizada em 2013 pelo Ministério da Ciência, Tecnologia e Inovação existem 94 iniciativas de parques tecnológicos conhecidas, sendo que 28 estão em processo de implantação, 28 estáo em operação e 38 estáo em fase de projeto, com 939 empresas instaladas gerando 32.237 postos de trabalho, destes, 17.630 são de nível superior (мCTI, 2014). Eles estimulam atividades econômicas de alto valor agregado, a geraçáo de empregos qualificados (característica das atividades de base tecnológica) e atraçáo e desenvolvimento de novas atividades econômicas (Damião, Catharino \& Zouain, 2006).

A existência dos EI implica na melhoria da competitividade não só do sistema industrial e das empresas, mas evidencia também o papel das regióes urbanas. De fato, os EI consolidam-se em áreas urbanas "ricamente informadas" com infraestrutura tecnológica, social, econômica, cultural e cientifica (Duarte, 2005). As cidades são vistas como centros de conhecimento, como loci de culturas que produzem e valorizam conhecimento (Knight, 2008, Leite \& Awad, 2012; May \& Perry, 2011a, 2011 b; Yigitcanlar, Velibeyoglu \& Baum, 2008). Yigitcanlar (2011) acrescenta que as cidades transformam-se dentro de um contexto de competição global para atrair e reter investimentos e talentos com o intuito de fomentar o desenvolvimento em seus territórios. 
De acordo com Hearn (2008) há quatro características da economia do conhecimento na vida das cidades: i) o crescimento econômico baseado em contínuas ondas de inovação, fazendo com que as cidades precisem acomodar ciclos curtos e rápidos de inovação; ii) os novos produtos e serviços estão fortemente pela dinâmica de redes que envolvem integração de funcionalidades, pessoas e empresas, fazendo com que o planejamento urbano necessite dar suporte a esta dinâmica de forma escalonável e mais aberta possível; iii) o envolvimento de conhecimento multidisciplinar para que a inovaçáo aconteça, impondo aos planejadores a necessidade de meios de convergência de diferentes domínios de conhecimento e, finalmente, iv) a nova identidade cultural das cidades fortemente influenciada pela chamada indústria criativa.

O cenário assim definido, tendo por um lado uma demanda de desenvolvimento dos EI e, por outro lado, a necessidade de integração destes ao meio urbano de forma adequada e sustentável, motiva o presente trabalho. A práxis tem demonstrado que esforços neste sentido têm tido desdobramentos favoráveis à criação e indução dos EI, relevando particular interesse dos formuladores de políticas públicas, das empresas e da academia (Spinosa \& Krama, 2014).

Para apreender parte da dinâmica urbana este trabalho assume o conceito de Desenvolvimento Urbano Baseado em Conhecimento (DUBC), o qual propóe abordagens de planejamento de modo a propiciar condiçóes urbanas que estimulem o surgimento e crescimento de empresas de inovação de base tecnológica, estimulando igualmente a diversidade social e princípios de sustentabilidade ambiental (Knight, 1995; Yigitcanlar, 2010, 2011). Assim, uma análise detalhada da relação entre o DUBC e os EI é aqui apresentada, tendo como base um modelo conceitual especificamente desenvolvido. A título de complementação empírica, o modelo foi aplicado para se obter uma analise em quatro cidades detentoras de premiados eI brasileiros.

\section{Modelo conceitual e aplicação}

O modelo teve sua construção fundamentada na triangulação de métodos (Minayo, Assis \& Souza 2005) que por sua vez se apoiou em abordagens tradicionais de pesquisa social (Gil,1999; Malhorta \& Taylor, 2008). Para o entendimento do DUBC a pesquisa bibliográfica e documental privilegiou uma visão aplicada e focou-se em estratégias e indicadores urbanos que permitem medir a operacionalização do DUBC. Os EI também foram abordados de forma aplicada por meio de estudos descritivos de ecossistemas no mundo. Para os EI o foco foi o desempenho verificado a partir de indicadores de resultados e impactos esperados. Distinguem-se resultados como sendo avanços ou retrocessos diretamente mensuráveis, de impactos vistos como consequências não mensuráveis e observáveis a partir dos resultados.

Determinantes oriundos das duas áreas foram organizados em um modelo inicial que racionalizou as relaçóes por meio de um processo de dedução tradicional (figura 1). O DUBC produziu as variáveis independentes e os EI as variáveis dependentes do modelo. O foco está em relaçóes causa-efeito, sendo as causas as perspectivas estratégias do DUBC e os efeitos o desempenho dos EI. Ao todo, 85 relaçôes são analisadas. Duas delimitaçóes são apresentadas pelo modelo: i) não são consideradas relaçóes contrárias dos EI para o DUBC (situaçóes onde os resultados 
e impactos influenciam uma ou várias perspectivas) e ii) não há consideração de relaçôes desfavoráveis. Esta opção permite focar prioritariamente na identificação de recomendaçóes para os formuladores de políticas públicas e planejadores urbanos envolvidos com o DUBC.

\section{FIGURA I $\mid$ O modelo conceitual}

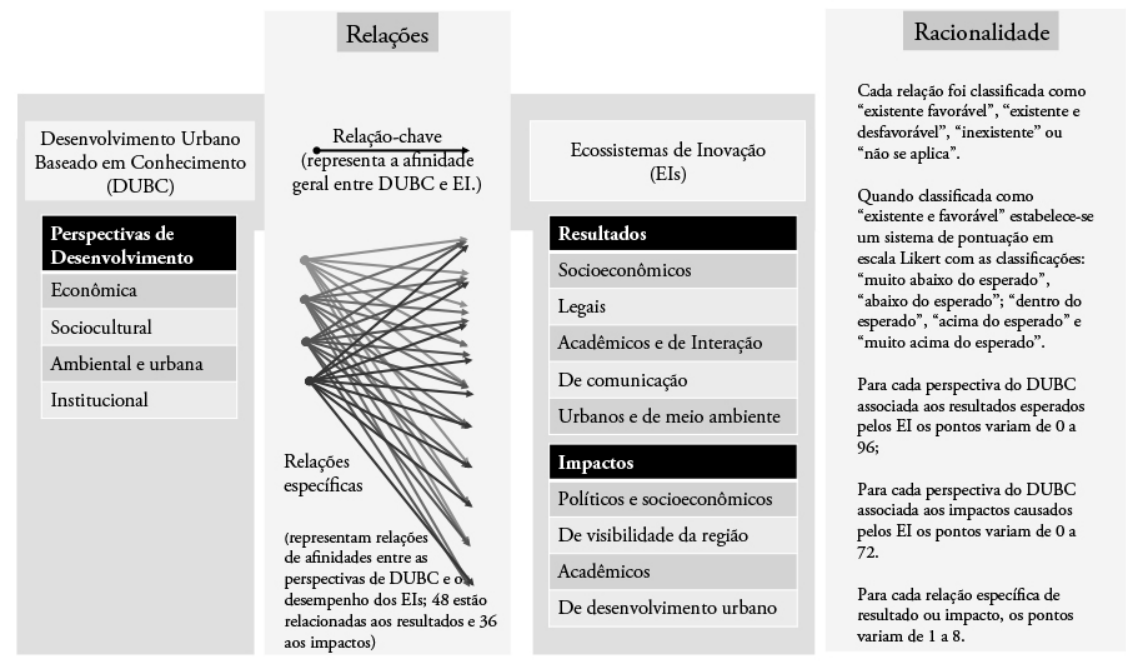

FONTE ELABORAÇÃo PRÓPRIA

Um instrumento para coleta da percepção de gestores de EI foi desenvolvido por meio do programa computacional Qualtrics ${ }^{\mathrm{R}}$ e aplicado para verificar a coerência do modelo inicial. Ajustes e melhorias foram produzidas e geraram a versão final do modelo e do instrumento. Visitas e entrevistas foram realizadas em quatro cidades brasileiras que abrigam EI vencedores do "Prêmio Nacional de Empreendedorismo Inovador" concedido anualmente pela Associação Nacional de Entidades Promotoras de Empreendimentos Inovadores no Brasil (tabela 1). Os critérios de premiação dos EI são fundamentados na visão de futuro, responsabilidade social e ética, decisões baseadas em fatos, valorização das pessoas, abordagem por processos, foco nos resultados, inovação, agilidade, aprendizado organizacional e visão sistêmica (Associação Nacional de Entidades Promotoras de Empreendimentos Inovadores [Anprotec], 2008). As entrevistas buscaram obter a percepção dos principais atores submetidos às estratégias de DUBC e, ao mesmo tempo, envolvidos com a gestáo dos EI. Uma percepção de qualidade sobre essa relação é privilégio de pessoas com conhecimento aprofundado em gestão da inovação. As entrevistas ficaram desta forma restritas aos diretores de inovaçáo e/ou competitividade de cada EI, totalizando 8 entrevistas diretas. 
TABELA I | Ecossistemas brasileiros analisados

\begin{tabular}{|c|c|c|c|c|c|}
\hline CIDADE EI & POPULAÇÃO & ÁREA (KM2) & $\begin{array}{c}\text { DENSIDADE } \\
\text { DEMOGRÁFICA } \\
\text { (HAB/KM2) }\end{array}$ & $\begin{array}{l}\text { PIB (PRODUTO } \\
\text { INTERNO BRUTO } \\
\text { EM MIL REAIS) }\end{array}$ & $\begin{array}{c}\text { PIB PER } \\
\text { CAPITA } \\
\text { (EM REAIS) }\end{array}$ \\
\hline \multirow[b]{2}{*}{ Recife } & 1.537 .704 & 218.435 & $7.039,64$ & 30.176 .875 & $19.624,63$ \\
\hline & \multicolumn{5}{|c|}{$\begin{array}{l}\text { Porto Digital - que começou a operar em } 2001 \text { um dos maiores polos de tecnologia e } \\
\text { inovaçáo do país. Atençáo especial às duas incubadoras e uma aceleradora de startups. } \\
\text { Concentra-se em sistemas de gestão empresarial, mobilidade urbana, games, animação e } \\
\text { aplicaçóes para dispositivos móveis, redes neurais e inteligência artificial para finanças e } \\
\text { processos bancários, segurança de dados, ensino e entretenimento a distância, e outsour- } \\
\text { cing. Hospeda } 7.100 \text { funcionários em } 250 \text { empresas }\end{array}$} \\
\hline \multirow[b]{2}{*}{$\begin{array}{l}\text { Rio de } \\
\text { Janeiro }\end{array}$} & 6.320 .446 & 1.200 .278 & $5.265,82$ & 190.017 .531 & $30.088,24$ \\
\hline & \multicolumn{5}{|c|}{$\begin{array}{l}\text { Parque Tecnológico da Universidade Federal do Rio de Janeiro (PT do RJ), inaugurado } \\
\text { em } 2003 \text {, com a missão de criar um ambiente de cooperação entre a iniciativa empreen- } \\
\text { dedora e a comunidade acadêmica visando ao fortalecimento da capacidade de inovaçáo. } \\
\text { Ressaltam-se as áreas de energia, petróleo e sustentabilidade. Envolve } 1.500 \text { pessoas em } 46 \\
\text { empresas. }\end{array}$} \\
\hline \multirow[b]{2}{*}{$\begin{array}{l}\text { Porto } \\
\text { Alegre }\end{array}$} & 1.409 .351 & 496.682 & $2.837,53$ & 42.947 .485 & $30.524,80$ \\
\hline & \multicolumn{5}{|c|}{$\begin{array}{l}\text { TECNOPUC, ligado à Pontifícia Universidade Católica do Rio Grande do Sul e inaugu- } \\
\text { rado em 2003, é multissetorial, focado em quatro áreas: tecnologia da informação e } \\
\text { comunicação e eletroeletrônica; energia e meio ambiente; ciências biológicas, da saúde e } \\
\text { biotecnologia e indústria criativa. Abriga } 6,3 \text { mil postos de trabalho. O TECNOPUC está } \\
\text { inserido no contexto da Porto Alegre Tecnópole e envolve agências de fomento do Gover- } \\
\text { no (FAPERGS, FINEP, CNPq, etc.), entidades privadas (SEBRAE, ANPROTEC, FIERGS, etc.) e } \\
\text { entidades específicas da área de C\&T (MCT, COMCET), além de } 120 \text { empresas. }\end{array}$} \\
\hline \multirow[b]{2}{*}{$\begin{array}{l}\text { São } \\
\text { Leopoldo }\end{array}$} & 214.087 & 102.738 & $2.083,82$ & 4.077 .412 & $19.044,32$ \\
\hline & \multicolumn{5}{|c|}{$\begin{array}{l}\text { TECNOSINOS - criado em 2009, com iniciativas datadas desde 1999, sua governança se } \\
\text { estabelece entre a unisınos (Universidade do Vale do Rio dos Sinos, onde está localizado } \\
\text { o parque), Associação Comercial, Industrial e de Serviços de São Leopoldo (Acis/sL), } \\
\text { Associação das Empresas Brasileiras de Software e Serviços de Informática - Regional do } \\
\text { RS (Assespro/Rs), Sindicato das Empresas de Informática do Estado do RS (Seprorgs), } \\
\text { Sociedade Sul-Rio-Grandense de Apoio ao Desenvolvimento de Software (Softsul) e } \\
\text { Prefeitura Municipal de São Leopoldo. O TECNOsınos possui especialidades nas áreas de } \\
\text { tecnologia da informação, automação e engenharias, comunicação e convergência digital } \\
\text { alimentos funcionais e nutracêutica e tecnologias socioambientais e energia. }\end{array}$} \\
\hline
\end{tabular}

\section{Análises}

Do uso do modelo emergiram cinco principais constataçóes que caracterizam o relacionamento entre o DUBC e os EI.

\section{\# 1: Há importantes similaridades conceituais entre o DUBC e os EI justificadas pela gênese comum de ambos.}

Tanto o DUBC quanto os EI podem ser considerados arranjos ocorridos em resposta à necessidade de inserção de regióes na economia do conhecimento. Declaraçóes definidoras de ambos permitem identificar várias similaridades.

O DUBC é definido como uma nova estratégia de desenvolvimento territorial para a geraçáo de riqueza tendo como elemento central a promoçáo da capacidade de atrair, gerar reter e fomentar a criatividade, o conhecimento e a inovação (Yigitcanlar, 2011). O conceito de DUBC envolve uma missão estratégica para incentivar 
e nutrir a produção local da ciência, inovação e criatividade no contexto de uma economia do conhecimento em expansão e na sociedade. Uma cidade que prioriza o DUBC pode ser vista como uma cidade integrada, que combina fisicamente e institucionalmente as funçóes de um parque de ciência com funçóes cívicas e residenciais, oferecendo um paradigma eficaz para as cidades sustentáveis do futuro (Knight, 2008; Yigitcanlar, Velibeyoglu \& Baum, 2008).

Já o termo ecossistema de inovação ganhou maior uso em publicaçóes recentes e tem integrado discussóes sobre "regiôes de inovação", "millieu innovateur" (ambientes inovadores), "clusters" conforme o uso estabelecido por Porter na década de 1990 (Porter, 1990; Rosenfeld, 1996) e "clusters de inovação globais" (Engel, 2014). Um "ecossistema de inovação", ou "EI", pode ser definido como uma iniciativa, espontânea ou induzida, abrangente e flexível, onde fatores independentes que atuam de forma conjunta, porém bastante aleatória, viabilizam a ação de empreendedores e inovadores, permitindo que a inovaçáo ocorra segundo um processo sustentado num determinado território (Schlemm, Spinosa \& Reis, 2015). Os EI caracterizam-se como lugares propícios ao empreendedorismo inovador e de desenvolvimento contínuo de inovaçôes. Lugares que constituem espaços de aprendizagem coletiva, de intercâmbio de conhecimento, de práticas produtivas e de processos inovativos, os quais envolvem o exercício da criatividade, da capacidade de gerar e integrar conhecimento e da capacidade de desenvolvimento e difusão de novos produtos e serviços (Spinosa \& Krama, 2014).

Em suma, vários elementos considerados na formação de EI estão normalmente imbricados no meio urbano e são objetos de atençáo do DUBC. Alguns elementos que podem ser assumidos na interação DUBC-EI: governo (legislação, regulaçóes, incentivos), demanda, cultura, empreendedores (educação e rede de relacionamentos), infraestrutura (física e serviços), financiamento e invençóes (universidades, centros de P\&D e inovação aberta).

\#2: $O$ DUBC e os EIs são manifestações socioténicas que ocorrem associadas ao meio urbano. Há intríseca relaçáo do DUBC com o meio urbano, enquanto que para os EIs esta relaçâo é importante, mas nâo obrigatória.

O DUBC pode ser percebido como uma manifestação sociotécnica face ao surgimento de um novo perfil de cidade, a qual deixou de ser industrial para ser baseada no conhecimento. As cidades se convertem cada vez mais em nós de uma rede multidimensional de processos técnicos, científicos e artísticos, concentrando e atraindo pessoas responsáveis pela "produção da subjetividade" isto é, pela germinação da criatividade cultural, tecnológica e econômica que animam a atual sociedade. As cidades são "formadas e formadoras da diversidade, atratoras e dispersoras de valores que nelas se transformam", cuja força está tanto em possíveis características físicas quanto na dinâmica de fatores políticos, culturais, econômicos, financeiros, sociais e técnicos. Empresas e pessoas inovadoras dependem de um ambiente informacionalmente rico e esse ambiente está intimamente ligado às qualidades do contexto urbano (Duarte, 2005).

Os EI também podem ser caracterizados como manifestaçôes sociotécnias, envolvendo instrumentos decorrentes de políticas públicas urbanas, estimulando a 
formação e o crescimento de empresas de alta tecnologia e, por vezes, envolvendo-se com a revitalizaçấo de áreas urbanas degradas ou economicamente deprimidas. EI privilegiam a sinergia entre os centros locais de ensino superior e de pesquisas com as empresas, visando à criação de massa crítica de empresas baseadas no conhecimento que se instalam na região ou, de forma mais avançada, que formam clusters (Schlemm, Spinosa \& Reis, 2015).

Tanto o DUBC como os EI observam tendência de "desmaterialização" da produção, significando menor consumo de matéria-prima, menores espaços e necessidade de ampliação do conhecimento, com trabalhadores muito qualificados e relativamente mais bem remunerados (Alvim, 2005). As relaçóes entre empresas com o meio sócio-político-cultural não são apenas mercantis, mas também informais capazes de gerar externalidades positivas produtivas para o conjunto das empresas (Alvim, 2005). Mais, para ambos tem sido prática do poder público instaurar estratégias de desenvolvimento econômico e urbano com o propósito de aliar o enfrentamento da crise socioeconômica com a territorial resultante das novas configuraçóes de produçáo, por meio do desenvolvimento de uma cidade eficiente, atraente e equitativa. Nesse sentido, "o planejamento urbano, associado às iniciativas vinculadas às novas formas de produção, pode vir a contribuir na redefinição de desenvolvimento local" (Alvim, 2008).

Deve-se considerar que nem todos os EI se desenvolvem inseridos no meio urbano, apesar de considerarem importante esta relação. No Brasil, alguns EI históricos foram criados, longe do meio urbano e próximos à determinadas áreas tecnológicas de interesse. Este é o caso do sistema Embrapa (Empresa Brasileira de Pesquisa Agropecuária), reputado nacionalmente por inovaçóes agroindustriais, possuindo presença em diversas localidades rurais do Brasil. Outros casos mais recentes têm ocorrido por motivação imobiliária. Em cidades onde o custo de ocupação do solo é alto, grupos de investidores têm se organizado para a instalação de EI em áreas menos valorizadas e próximas ao meio urbano. Estes empreendimentos tem o formato de condomínios que buscam harmonizar trabalho, moraria e lazer, induzindo-se a valorização da nova área por meio de benfeitorias em infraestruturas, da atração de centros de pesquisa, centros de formaçâo, unidades de P\&D de empresas e serviços de apoio. Um empreendimento significativo a ser considerado com estas características é o Cidade Pedra Branca no Sul do Brasil.

\section{\#3: Há convergência de interesses e de atuação dos DUBC e dos EIs, principalmente no que diz respeito à inovaçâo.}

Ambos atuam com vistas a obter benéficos econômicos e sociais, envolvendo múltiplos ativos que estáo imersos em complexas interaçóes que precisam ser induzidas, nutridas e gerenciadas. Inovação, no seu sentido mais amplo, constitui um importante ponto de convergência. O sucesso da inovação envolve compreender e moldar o ambiente urbano de maneira a melhorar o desempenho inovador, considerando fatores mais amplos que condicionam o comportamento da sociedade. Estes fatores incluem especialmente a estrutura institucional e organizacional da economia e, em particular, suas infraestruturas e processos que criam e distribuem conhecimento científico (Smith, 2000). 
A inovação não é apenas associada ao setor industrial, mas abrange cada vez mais a distribuição e serviços de apoio, tampouco se resume ao campo da tecnologia. Segundo Arbix (2007) inovação se desenvolve num invólucro de incertezas; a compreensão de seus mecanismos mais sutis exige intenso tratamento multidisciplinar e é fundamentada na busca pelo domínio de novas tecnologias, facilidade na introdução de novos modelos de negócio, de produtos, de organização, de gestão e de todos os processos intensivos em conhecimento.

A inovação tem encontrado no meio urbano um cenário favorável ao seu desenvolvimento devido à existência e convergência de diversos atores. Têm-se observado a emergência de um perfil urbano que concentra num espaço de proximidade empresas e universidades. Nestes espaços percebe-se a intenção de desenvolvimento sustentável, levando formuladores de políticas a adotar mecanismos mais abrangentes que incluam não somente a dimensão econômica e social, mas também cultural, ambiental e territorial (Spinosa \& Moura, 2013).

\section{\#4: O DUBC pode influenciar positivamente os EIs.}

Esta constatação decorre da harmonia conceitual, da convergência de interesses e de atuação do DUBC e dos EI (itens \#1 e \#3 antes elencados), bem como de evidências obtidas dos quatro ecossistemas selecionados. De fato, a influência do DUBC sobre os EI foi considerada positiva em todas as perspectivas ("dentro do esperado", "acima do esperado" e "muito acima do esperado") (figura 2). Esta percepção autoriza uma investigação mais detalhada das perspectivas do DUBC e constitui a principal contribuição deste trabalho.

\section{FIGURA 2 Influência do DUBC no desempenho dos EIs, por perspectivas}

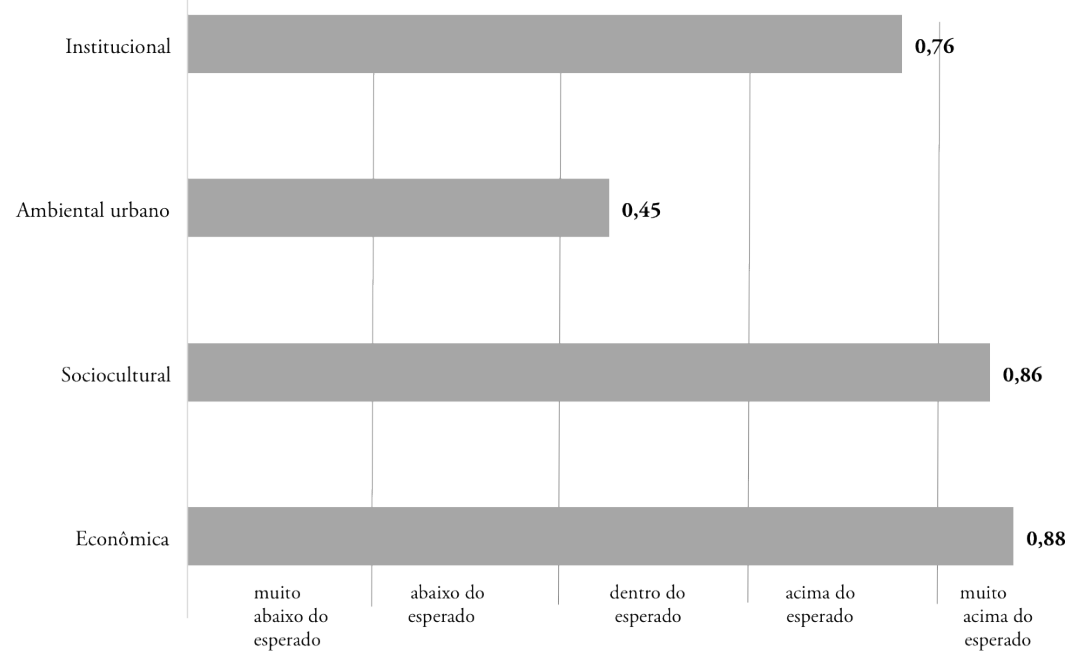

FONTE ELABORAÇÃO PRÓPRIA 


\section{Perspectiva econômica}

A perspectiva econômica do DUBC baseia-se em fundamentos de macroeconomia que sustentam a economia do conhecimento e considera o conhecimento como um recurso estratégico e vital para as cidades (Yigitcalar, 2010). Sugere-se promover ativos de conhecimento no centro das atividades econômicas das cidades e fomentar a produção e incorporação local do conhecimento em vez de considerá-lo exógeno, importado e suplementar. Busca-se incrementar o número de indústrias e negócios baseados em conhecimento, o número de centros de $\mathrm{P} \& \mathrm{D}$, os investimentos externos, o número de empresas multinacionais, indústrias e negócios criativos, de patentes registradas, entre outras. Uma vez que conhecimento passa a ser o principal referencial econômico, um importante desafio passa a ser a sua geração no meio urbano, a qual é transdisciplinar, socialmente distribuída, variável, heterogênea e cujos mecanismos de comunicação são mais densos e horizontais (Gibsons, 1994). Van Wezemael (2008) propóe uma teoria denominada "assemblage" no contexto das cidades do conhecimento, baseada na experimentação, criatividade e na construçâo de espaços de aprendizagem. Os trabalhos de Nonaka e Takeuschi (1995) e Nonaka e Konno (1998) no contexto organizacional também são de interesse e fundamentam a teoria da "assemblage".

\section{FIgURA 3 | Influência do DUBC no desempenho dos EIs, por cidades}

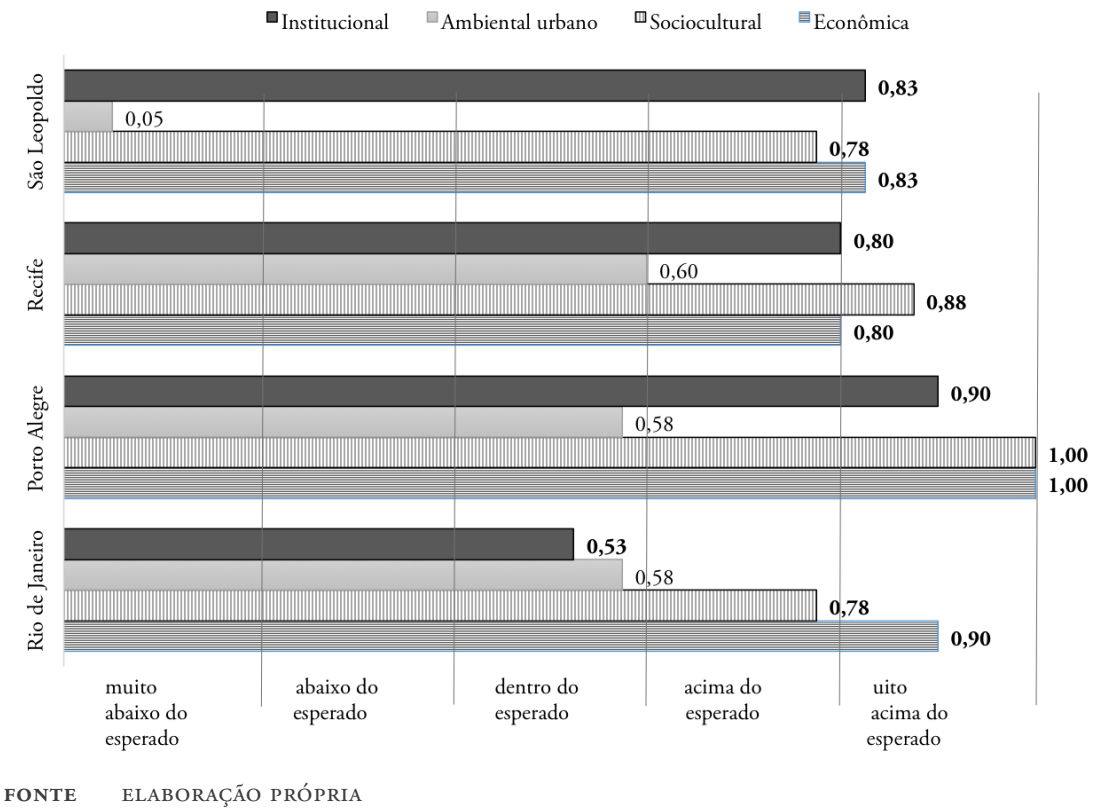

A relação entre estes preceitos e o desempenho econômico dos EI é de fácil constatação conceitual. Conhecimento é de fato a matéria-prima, matéria em transformação e matéria transformada para o funcionamento dos EI. Quanto mais valorizada nas cidades a atividade baseada no conhecimento: i) mais inputs terão os EI, 
ii) mais relevante será a atuação dos mesmos como mecanismos de transformação destes insumos em novas tecnologias, novos produtos, novos processos e novos serviços, iii) aumento de geração de outputs de maior interesse econômico, iv) maior possibilidade de envolvimento de setores produtivos correlatos que veráo no EI uma oportunidade de agregação de valor à sua atividade, gerando naturalmente maior desempenho econômico, e, principalmente, v) melhores chances os EI terão de atingir os objetivos de geração de riqueza. Em suma, a perspectiva econômica do DUBC adequadamente integrada aos EI eleva a produção da inovaçáo local e aumenta a competitividade em relaçáo a outras cidades. Os EI passam a ser considerados como ativos de competitividade urbano e regional, capazes de adicionar alto valor às atividades econômicas dos sistemas produtivos e/ou dos setores intensivos em conhecimento da região ou fora dela.

Nos casos estudados, a perspectiva econômica é a que mais tem influenciado no desempenho dos EI, sendo classificada de forma geral como "muito acima do esperado” (figura 2). Mais especificamente, a influência foi maior em Porto Alegre, seguida respectivamente do Rio de Janeiro e São Leopoldo, estas três "muito acima do esperado", e Recife, percebida como "acima do esperado" (figura 3). Ressaltam-se as constataçóes, tendo como base os pontos defendidos pela perspectiva econômica:

- A alta prevalência dos fatores econômicos sobre os demais fatores (sociocultural, institucional e ambiental urbano) deve-se a uma política brasileira promotora da inovação que enfatiza sobremaneira o desempenho econômico. Nela, a inovação está fortemente ligada ao retorno financeiro pelo atendimento de mercados por novos produtos e serviços por parte das empresas formadoras dos EI.

- Considerando que o DUBC tem na sua gênese a motivação do desenvolvimento pelo viés econômico (economia do conhecimento), entende-se natural que os esforços realizados pela perspectiva econômica sejam privilegiados e constituam fator vital na promoção da dimensão econômica dos EI. Esta percepção corrobora o identificado na literatura que coloca o conhecimento como ativo central e motor da nova economia (Yigitcanlar, 2010; Word Bank, 2010).

- Não há de fato uma produção de conhecimento sistematizada e sofisticada no meio urbano no qual os EI analisados estáo inseridos, apesar de existirem propostas para tal. Há na maioria das situaçóes uma relação de transferência de tecnologia entre universidades e centros de P\&D para as empresas nos modelos mais tradicionais de encomenda (contratos de prestação de serviços) ou de oferta de pesquisas em busca de demanda (feiras de tecnologia ou de inovaçáo). Pouco se constatou em termos de possibilidade de geração de conhecimento a partir de outros ativos urbanos além das universidades e centros de P\&D.

Há de se considerar que as constataçôes 1 e 2 são consequência das políticas públicas brasileiras até então executadas. Estas políticas consideravam o desenvolvimento da inovação como parte de políticas de desenvolvimento industrial mais amplas, sendo as mais significativas a PITCE (Política Industrial, Tecnológica e de Comércio Exterior - 2004 a 2008), a PDP (Política de Desenvolvimento Produtivo - 2008 a 2010) e PBM (Política Brasil Maior - 2011 a 2014) (ABDI, 2016). Algo comum a 
estas políticas era a orientação top-down (do Governo Federal, para os Governos Estaduais, até as Regióes), buscando reduzir as diferenças regionais do Brasil, por meio de resultados econômicos e com ênfase no escopo industrial e nos sistemas produtivos. O foco era fortalecer setores econômicos com potencial de elevarem a competitividade do País como um todo. Muito pouco foi orientado a economia urbana ou regional e as cidades e seus ativos foram vistos como simples meios para atingir estes fins. As cidades não constituíram foco efetivo destas políticas e, salvo algumas exceçóes, esta dinâmica levou a maioria dos EI no Brasil a se caracterizarem como "ilhas econômicas", não totalmente integrados ao meio urbano e não sendo efetivos partícipes da economia local. Uma evidência da falta de atenção a esta integração no Brasil é a ausência de indicadores de desempenho e pesquisas que explicitem o desenvolvimento da economia urbana alavancada por atividades empreendedoras e de inovação.

\section{Perspectiva sociocultural}

Esta perspectiva do DUBC diz respeito ao capital sociocultural que uma cidade oferece. Ela propóe uma valorização da sociedade que atinge a equidade social através de capitais humano e social fortes, de diversidade e de independência (Yigitcanlar, 2010). Atividades socioculturais vibrantes, associadas a ricos ambientes naturais conservados, a ambientes construídos de qualidade, onde há tolerância e aceitação do multiculturalismo, democracia, transparência, governança visionária, desempenham papel fundamental nestas sociedades (Florida, 2005). Ela sugere, dentre outros, meios de encontros casuais e a combinaçáo de conhecimentos de fontes inesperadas que promovam inovaçóes, levando ao aumento do número de instalaçóes culturais e a promoção de eventos culturais.

Por conseguinte, esta perspectiva diz respeito ao trabalhador do conhecimento, uma vez que se dedica ao incremento do capital intelectual. Estes trabalhadores distinguem-se por terem no conhecimento seu principal instrumento de trabalho, estão acostumados a atividades não rotineiras, e são capazes de criar novas soluçôes ou adicionar valor às já existentes (Davenport, 2005; Florida, 2002, 2005; Pyöriä, 2005). Engenheiros, físicos, matemáticos, profissionais da computaçáo, arquitetos, cientistas, advogados são alguns dos exemplos desta classe. A participação de centros de formação e profissionalização passam assim a ser fundamentais na viabilização da perspectiva sociocultural. Estes centros trazem para a regiáo mais estudantes, pesquisadores e profissionais capacitados que, acima de tudo, qualificam a região, relacionando-a ao capital humano criativo (Leite \& Awad, 2012). Na prática esta perspectiva busca elevar a proporção da população com formação superior e de trabalhadores do conhecimento face à população em geral. O esforço é direcionado para a valorização e acesso à educação qualificada voltada para as áreas intensivas em conhecimento.

Conceitualmente, os desdobramentos dos pontos advogados pela perspectiva sociocultural sobre os EI são significativos, em particular os EI envolvidos com a indústria cultural ou criativa (Hesmondhalgh, 2007; Howkins, 2013). Uma base cultural rica e diversificada é considerada fator-chave para o sucesso de EI (Brown $\&$ Ulijn, 2004; Moulaert \& Nussbaumer, 2005; Schlemm et al., 2015). Reconhece-se, 
além da diversidade de atores econômicos, cada vez mais a diversidade de tecido étnico, cultural e social, todos pré-requisitos para uma dinâmica de inovação contemporânea (Hwang \& Horowitt, 2012). Desta base emergem a criatividade e o espírito empreendedor, ingredientes essenciais à inovação. Florida (2005) afirma que as atividades baseadas em conhecimento e criatividade se desenvolvem melhor em algumas regiôes considerando certas condiçóes sociais, culturais e institucionais de seu território.

Empiricamente, considerando os casos estudados, a perspectiva sociocultural do DUBC foi a segunda a influenciar positivamente os EI, obtendo uma percepção geral "muito acima do esperado" (figura 2). Especificamente, em Porto Alegre e Recife foi percebida uma influência "muito acima do esperado" e no Rio de Janeiro e São Leopoldo "acima do esperado" (figura 3). Cabem as seguintes observaçóes:

- Uma evidência a esta significância repousa no crescimento da indústria criativa no Brasil. Na última década houve um crescimento de $69,1 \%$ no número de empresas e de 69,8\% do PIB do setor (Federação da Indústrias do Estado do Rio de Janeiro [FIRJAN], 2014). Destaca-se Recife quando no ano de 2010 foi criado o Centro de Empreendedorismo e Tecnologia da Economia Criativa -Portomídia-, um projeto que tem por objetivo a estruturação de empreendimentos nascentes da economia criativa, mais especificamente nas áreas de design, jogos digitais, multimídia, cine-vídeo-animação, música e fotografia que façam uso intensivo de tecnologia da informação e comunicação (TIC) e do design. Porto Alegre declara igualmente que parte de suas atividades está voltada à indústria criativa.

- A presença de centros de formação de trabalhadores do conhecimento é facilmente percebida nas quatro cidades, uma vez que Universidades estấo entre os principais stakeholders, confundindo-se com as próprias atividades dos EI. No Porto Digital, há a participação de uma instituição de ensino superior, o Cesar. edu, iniciativa do Centro de Estudos e Sistemas Avançados do Recife (Cesar). A gênese do Tecnopuc de Porto Alegre é a Pontifícia Universidade Católica do Rio Grande do Sul, ainda principal stakeholder do EI. No Rio de Janeiro a participação da Universidade Federal do Rio de Janeiro ocupa a posição de principal provedora de egresso para o PT da UfRJ. Já o Tecnosinos de São Leopoldo apoia-se fortemente na Universidade do Vale do Rio dos Sinos.

- Uma iniciativa associada ao Tecnopuc se destaca na indução do número de trabalhadores do conhecimento e na formação de cultura à inovação. Trata-se do Museu de Ciências e Tecnologia, um canal para despertar o interesse da população local para a ciência em crianças, jovens e mesmo adulto, por meio de coleçôes e experimentos científicos. O Museu é um relevante laboratório que permite pesquisa de mestrandos e doutorandos provenientes de várias partes do mundo.

Nota-se que a quase totalidade da dinâmica sociocultural de interesse dos EI tem sido promovida pelos próprios eI e não pelas regióes onde estáo inseridos. Isto se deve, em parte, ao fato das localidades ainda não terem absorvido de forma mais intensa e integrada o "subsistema" sociocultural dos EI no meio urbano. Esta situação 
pôde ser justificada, principalmente, pela histórica diferença socioeconômica do Brasil, que reflete na organização de suas cidades. Os eI são considerados como espaços (por vezes territorialmente definidos) de uma classe socioeconomicamente privilegiada, sendo o acesso a estes espaços algo não natural pelas classes menos favorecidas (proporcionalmente superior em número de habitantes). Esta situação leva ao desafio, pouco observado pelos gestores dos EI, de maior envolvimento dos cidadãos comuns, daqueles indiretamente atingidos pelos EI. A atuação do poder público na governança dos EI, seja municipal ou regional, torna-se significativa para fazer prevalecer esta intenção.

Observou-se também esforços dos EI em aumentarem a oferta de trabalhadores do conhecimento, além das Universidades que originaram os EI, a partir de outras instituiçóes localizadas em outras áreas das cidades, principalmente na formação de nível técnico. Estas instituiçôes têm potencial elevado de contribuição para os EI a um nível não atendido pelas Universidades. O sucesso desse esforço ainda é considerado aquém do potencial de interação, devido a dificuldade de conciliação de interesses das instituiçôes externas aos EI, bem como pela pouca autonomia acadêmica do sistema de ensino brasileiro. As empresas, de forma recorrente, observam que as instituiçôes de ensino (inclusive as Universidades) não contemplam flexibilidade suficiente para acomodar especificidades na formação de profissionais locais. Um exemplo é a formação, em tempo competitivo, de técnicos em áreas emergentes e de interesse mais imediato das empresas. Neste sentido, as cidades podem constituir centros de formaçáo municipais, mais vocacionados à realidade sociocultural e econômica de suas regióes.

\section{Perspectiva institucional}

Democratizar o acesso ao conhecimento, institucionalizando processos específicos nas organizaçóes de interesse (p.ex. processos de aprendizagem coletivos e interdisciplinares), com vistas a construir liderança, governança e planejamento fortes voltados à economia do conhecimento, é a principal proposta da perspectiva institucional do DUBC (Yigitcanlar, 2010). A participação da comunidade no processo é fundamental para o sucesso dos empreendimentos (Leite \& Awad, 2012). O desafio maior é mobilizar instituiçóes e atores estratégicos em torno destes propósitos.

Do ponto de vista conceitual, a perspectiva institucional caracteriza-se como uma alavancagem ao desempenho geral dos EI, justificada quando se observa a forma como os EI têm sido moldados no Brasil e em boa parte do mundo. Tipicamente eles buscam cooperação multi-institucional, caracterizada por um esforço integrado de empresas, academias e governos em prol da inovação, o que alguns pesquisadores denominam de abordagem hélice-tripla (Etzkowitz, 2008; Seidl, Longo, Etzkowitz \& Leydesdorff, 1999). Esta abordagem defende a criação de processos híbridos envolvendo os três stakeholders, a partir dos quais emergem novas formas de produção, transferência e aplicação de conhecimento. Tanto os elementos tangíveis (universidades, empresas, laboratórios, infraestrutura de conhecimento, de tecnologias da informação, redes) quanto os intangíveis (aprendizagem, conhecimento, educação e formação, capital intelectual, criatividade) devem ser considerados e apoiados nas estratégias de relacionamento, ou seja, na medida do possível, institucionalizados. Em última instância, 
instituiçôes são organizaçóes humanas e a cooperação ocorre idealmente no nível dos indivíduos ou da sua coletividade, em particular dos trabalhadores do conhecimento nos mais diversos cenários que não estão diretamente associados aos EI. Quanto mais forte for o relacionamento entre os indivíduos pertencentes aos setores produtivos, as universidades e aos centros de $\mathrm{P} \& \mathrm{D}$ num determinado território, melhores serão os resultados e impactos aferidos pelo EI.

Nos casos selecionados, a perspectiva institucional foi a terceira a influenciar positivamente os EI, obtendo uma percepção "acima do esperado" (figura 2). Especificamente se sobressaem Porto Alegre e São Leopoldo (muito acima do esperado), seguidos de Recife (acima do esperado) e Rio de Janeiro (dentro do esperado) (figura 3). Percebeu-se principalmente que:

- Os quatro EI absorveram intensivamente a abordagem hélice-tripla. O Porto Digital mobiliza, além do Centro de Estudos e Sistemas Avançados do Recife e a Universidade Federal de Pernambuco, 250 empresas. O pt da Ufru abriga mais de 50 organizaçóes, sendo 12 grandes empresas, 6 laboratórios, 6 pequenas e médias empresas e 31 startups. O Tecsinos conta com 30 empresas incubadas e 15 graduadas. O Tecnopuc abriga 120 organizaçôes, considerando empresas, entidades representativas e estruturas de pesquisa da PUCRs. Em todos, observa-se a participação, por vezes direta e por vezes indireta, de gestores públicos municipais e estaduais na governança dos EI.

- Há importante cooperação entre os trabalhadores do conhecimento internos às instituiçôes que compóem os EI. No entanto, assim como observado na perspectiva sociocultural, a participação dos cidadãos das cidades carece de intensificação.

- A governança do Porto Digital se sobressai em termos de integração com o desenvolvimento regional. Ele é gerenciado de forma privada por uma Organização Social sem fins lucrativos, o Núcleo de Gestão do Porto Digital. Além de ser a governança do Parque, também é um ponto de articulação de diversas instituiçóes voltadas para o desenvolvimento socioeconômico da cidade.

Percebeu-se em geral, a exemplo do que ocorre na grande maioria dos EI espalhados pelo Brasil, que a aplicação da abordagem hélice-tripla tem sido parcial, bem como tem carecido de atualizaçóes observadas nos últimos estudos da área (Cai, 2015). Estas atualizaçóes podem contribuir positivamente para o processo de institucionalização do esforço conjunto. Alguns pontos mais críticos podem ser elencados. Primeiro, há falta de cultura orientada ao mercado em boa parte das universidades brasileiras. Muitas universidades absorveram durante anos uma ideologia que advoga que atividades de ensino e pesquisa devam ser voltadas para necessidades puramente acadêmicas e náo aplicadas, o que desfavorece o relacionamento com empresas. Outras universidades, em particular as privadas, não institucionalizaram a pesquisa por, entre outros motivos, não a considerarem como fonte de receita expressiva, ou se ativeram ao mínimo legalmente necessário para serem classificadas no Brasil como universidades e não centros universitários e/ou faculdades. Segundo, processos orientados à gestâo do conhecimento transversais 
aos stakeholders carecem de maior qualidade e extensão. Estes processos têm sido implantados para auxiliar na transferência de conhecimento e tecnologia, mas são dedicados a situaçóes específicas e ficam normalmente restritos ao escopo universidade-empresa. Outros atores e outros modelos mais abrangentes deveriam ser considerados (Spinosa, Reis \& Schlemm, 2016). Terceiro, há baixa proteção da propriedade intelectual (patentes de invenção, modelos de utilidade, desenhos ou modelos industriais, marcas de fábrica ou de comércio, marcas de serviço, nome comercial e as indicaçóes de proveniência ou denominaçóes de origem) envolvendo os stakeholders. Há um esforço crescente, principalmente por parte das Universidades em propriedade intelectual, mas este esforço tem tido baixa efetividade no sistema produtivo e, de forma mais abrangente, gerado pouca riqueza para as localidades. Pelo lado das empresas, muitas têm optado pela não proteção devido aos custos e ao tempo excessivo dos processos legais no Brasil. Quarto, o envolvimento da sociedade civil começa apenas a despontar. Um exemplo é o aumento da participação de Organizaçôes Não-Governamentais nos Eı. Mas ações de envolvimento mais direto da sociedade civil organizada podem ser incrementadas. Quinto, há ainda ausência de percepção quanto a competência das Universidades e Centros de P\&D na geração e difusão de tecnologia e conhecimento. Muitas empresas ainda não percebem estes stakeholders como capazes de agregação efetiva de valor aos seus negócios. Esta situação leva à uma baixa capacidade de absorção do setor produtivo das novas tecnologias e conhecimento. Sexto, embora as políticas públicas tenham avançado consideravelmente na criação de estruturas/instituiçóes de suporte à inovação no Brasil, percebe-se ainda a necessidade de maior integração destas com as empresas e universidades.

Independente da maturidade institucional que se encontra os EI, a participação de planejadores ou gestores urbanos é por vezes direta e por vezes indireta. Em geral, deve-se observar, de acordo com a abordagem hélice-tripla, que o governo local é fundamental na governança dos EI. Através desta governança a alocação de recursos urbanos, das mais diversas naturezas, é frequentemente solicitada, podendo-se sempre estabelecer um trade-off com as Universidades e com as Empresas, a favor do desenvolvimento urbano e regional. O aumento da qualidade de vida da população local deve ser o fim almejado.

\section{Perspectiva ambiental e urbana}

Esta perspectiva advoga promover a conservação, o desenvolvimento e a integração dos ambientes natural e construído, estabelecendo uma relaçáo de rede espacial forte entre o desenvolvimento urbano e os clusters de conhecimento. O desafio está em produzir desenvolvimento urbano de forma única e sustentável, ecologicamente correta, com alta qualidade de vida e lugar (Yigitcanlar, 2010). De fato, para adaptar-se aos novos modelos de produção centrados em pessoas, criatividade e inovação há a necessidade de criação de um ambiente diferente do que era característico da produção industrial tradicional (Alvim, 2008; Leite \& Awad, 2012). Os espaços hoje valorizados são aqueles que promovem encontros, convivência, interaçóes criativas e empreendedoras, que favoreçam a criação de empresas locais, que preservam a paisagem natural e valorizam as construçôes de arquitetura icônica, com qualidade 
de vida, mobilidade e segurança. Essas são algumas das características diferenciais das cidades que se inserem na economia do conhecimento (Yigitcanlar, 2010).

Emergem três principais influências da perspectiva ambiental e urbana do DUBC sobre os EI. Primeiro, uma rede espacial forte entre o meio urbano e os clusters de conhecimento contribui sensivelmente para o desempenho dos EI. Os EI dependem fortemente da disponibilidade e acessibilidade de recursos para o desenvolvimento de produtos e processos de natureza inovadora a partir da aplicaçáo de conhecimento de natureza científica e tecnológica. Esta disponibilidade encontra-se muitas vezes na infraestrutura composta de instalaçôes, equipamentos e serviços tecnológicos, os quais adequadamente planejados fazem parte do meio urbano de forma organizada.

Segundo, recursos humanos de natureza científica e tecnológica constituem o elemento mais importante que o meio urbano pode propiciar. Um ambiente de qualidade facilita a atração e retenção de talentos (e suas empresas), fator primordial para existência de EI. Trabalhadores do conhecimento possuem usualmente formação e poder aquisitivo superiores. Para Florida (2002), estes trabalhadores sáo atraídos para locais de vitalidade cultural e variedade, constituindo-se de uma componente essencial do sucesso da cidade do conhecimento. Uma cidade do conhecimento bem sucedida pode ser descrita como uma cidade existente que sofreu regeneração, alimentada por criatividade, inovaçáo e estilo de vida (Florida, 2005). Retençáo de talentos também é preocupação constante em EI, resultando em esforço contínuo das organizaçóes para redução de turnover. Um trabalhador do conhecimento, quando deslocado de uma organizaçáo para outra leva consigo parte do capital da empresa (o capital intelectual) e náo apenas knowhow, mais característico de trabalhadores da economia tradicional. Estratégias e abordagens específicas têm sido estudadas há alguns anos para esse fim (Botha, Bussin \& De Swardt, 2011).

Terceiro, deve-se ainda considerar as possibilidades de regeneração urbana que decorrem da perspectiva ambiental. De fato, alguns ei têm sido associados com a recuperaçáo de áreas degradadas, atraindo para tais investimentos públicos e privados, além de proporcionar uma nova opção de negócios para estas áreas. Nas décadas mais recentes iniciou-se um processo de reestruturação produtiva, levando a fragmentação e descentralização do processo de produção e no aumento da racionalização dos processos, gerando unidades produtivas menores e menos especializadas. Como consequência muitas cidades acabaram sofrendo um intenso processo de desindustrialização (Leite \& Awad, 2012) e consequente degeneração de áreas urbanas. Açóes como atração de empresas de alta tecnologia, de institutos de pesquisa e universidades aliados à boa qualidade de vida urbana, entre outros, são utilizados como importante conjunto de instrumentos nos processos de regeneração urbana e na implementação de projetos urbanos inovadores (Leite \& Awad, 2012; Maldonado \& Romein, 2010).

$\mathrm{Na}$ análise dos casos selecionados, a perspectiva ambiental e urbana é a que menos influenciou positivamente os EI, obtendo uma percepçáo conjunta como "dentro do esperado" (figura 2). Especificamente se sobressaem Recife, Porto Alegre e Rio de Janeiro, todas "dentro do esperado" (figura 3). Chama a atenção para percepção de São Leopoldo considerada "muito abaixo do esperado". Cabem as seguintes avaliaçóes específicas: 
- No caso de São Leopoldo deve-se considerar uma questão conjuntural: o Tecnosinos náo disputa área construída com outras atividades urbanas na mesma intensidade que os demais casos analisados, minimizando assim a influência de conservação, desenvolvimento e a integração dos ambientes natural e construído. O Tecnosinos possui uma área de $144.000 \mathrm{~m}^{2}$.

- Compartilhamento de área urbana é mais intenso para os outros EI. O Porto Digital se estabeleceu numa área igual a $1.415 .000 \mathrm{~m}^{2}$, o Centro de Pesquisas Leopoldo Américo Miguez de Mello (Cenpes) numa área de $350.000 \mathrm{~m}^{2}$ e o Tecnopuc numa área de $54.000 \mathrm{~m}^{2}$. O Tecnopuc e o Porto Digital estáo integrados à um meio urbano complexo e dispóem de ambiente construído e natural herdados de outras atividades econômicas.

- Em termos de regeneração urbana chama a atenção à iniciativa de Recife. O Porto Digital está localizado no antigo Bairro do Recife, considerado patrimônio histórico e arquitetônico, local de nascimento da cidade portuária no ano de 1537. O Tecnopuc possui uma história similar, iniciada com a aquisição de uma área militar desocupada e contígua ao campus da PUCRs, na qual atividades tecnológicas e instalaçáo de empresas permitem hoje atividades de alto valor econômico.

- Houve consenso por parte dos gestores quanto à necessidade de promover soluçôes de acessibilidade e mobilidade no entorno das áreas para de fato constituírem uma rede espacial forte entre o desenvolvimento urbano e os clusters de conhecimento.

Em termos gerais, a exemplo de vários EI no Brasil, muitas das questôes urbanas e ambientais são tratadas como simples componentes para o funcionamento do ecossistema. Alguns exemplos são a (re)definição de zonas urbanas e rurais para atividades especiais de P\&D ou comerciais, o incremento da acessibilidade e mobilidade dos stakeholders, incremento de suporte em Tecnologias da Informação e Comunicaçáo. Poucos são os EI que percebem na perspectiva ambiental e urbana o seu verdadeiro potencial de contribuição. Uma justificativa a este cenário é a maturidade brasileira em termos de preservação ambiental e de área construída. Nos processos decisórios de planejamento, sejam eles urbanos ou empresariais, priorizam-se aspectos de desenvolvimento econômico e social. Questóes ambientais ficam assim sujeitas a estes desenvolvimentos.

No entanto, um importante instrumento que dispóem os stakeholders no Brasil, em particular o ente Governo Municipal, para efetiva integração dos EI aos ambientes natural e construído é o Plano Diretor Municipal, criado pelo Estatuto das Cidades (lei 10.257 de 10 de julho de 2001). O objetivo maior do Plano é estabelecer a política de desenvolvimento e de expansão urbana, definindo, entre outras, diretivas sociais econômicas e físico-territoriais. A ênfase está em promover a ordenação dos espaços voltados à atividade econômica, à habitação e ao lazer do Município, construindo uma estratégia de mudança para melhoria de qualidade de vida da comunidade local. Cada cidade pode desdobrar este objetivo maior em objetivos específicos a realidade local que se pretende transformar. Neste sentido, Porto Alegre com o 
projeto de lei $004 / 2012$, Recife com o projeto de lei $17.511 / 2008$ e o Plano Recife 500 anos, Rio de Janeiro com o Plano Diretor UfrJ 2010-2020 e São Leopoldo com a Lei 6125/06, são exemplos, embora iniciais, deste tipo de esforço.

\section{Conclusôes}

A pesquisa partiu do interesse em analisar relaçóes existentes entre o DUBC e os EI, com vistas a subsidiar formuladores e gestores de políticas públicas interessados em promover a inserção das cidades nas chamadas economia do conhecimento e da inovação. A pesquisa apontou uma harmonia entre as estratégias de DUBC e os esforços para obter resultados e impactos pelos EI. Mais precisamente, constatou-se que: i) há de fato uma relaçáo entre DUBC e os EI, devido a importantes similaridades conceituais justificadas pela gênese comum de ambos os domínios de conhecimento, ii) o DUBC e os EI são manifestaçôes sociotécnicas que ocorrem no meio urbano, havendo intrínseca relação do DUBC com este meio, enquanto que esta relação é desejável, mas não obrigatória para os EI, iii) há convergência de interesses e de atuação dos DUBC e dos EI e iv) o DUBC pode influenciar positivamente os EI, levando ao entendimento mais aprofundado das seguintes perspectivas de desenvolvimento:

- Econômica: entende-se que os esforços realizados no meio urbano para fomentar a produção do conhecimento constituem fator vital aos EI, uma vez que o conhecimento é ativo central e motor da nova economia.

- Sociocultural: o desempenho dos EI pode ser incrementado quando promovido nas cidades o capital humano, o capital social, a diversidade, com aumento de competências e conhecimento dos indivíduos. O aumento da oferta de trabalhadores do conhecimento torna-se fator crítico de sucesso.

- Institucional: esta perspectiva contribui com um ambiente institucional forte e dinâmico, moldado por cooperaçáo multi-institucional, integrando empresas, academia e governos. A criação de processos híbridos envolvendo os três stakeholders, a partir dos quais emergem novas formas de produção, transferência e aplicação de conhecimento, mais compatíveis com a economia do conhecimento, constituem base para o funcionamento dos EI.

- Ambiental e urbana: os EI podem se beneficiar de uma rede espacial forte entre o desenvolvimento urbano e os clusters de conhecimento, de qualidade de moradia, lazer e trabalho, todos critérios de atração e localização dos recursos humanos de natureza científica e tecnológica. Há também interesse comum de regeneração urbana.

A influência destas perspectivas foi verificada em quatro EI brasileiros. Os resultados foram prioritariamente influenciados pela perspectiva econômica do DUBC, seguindo-se das perspectivas sociocultural, institucional e finalmente ambiental. Já os impactos esperados apresentaram um nível de influência diferente, prevalecendo a perspectiva institucional, seguida da sociocultural, econômica e ambiental. Uma hipótese para esta diferença seria o escopo de tempo envolvido com os resultados e 
com os impactos. No primeiro, o escopo de tempo é menor, buscando preencher as expectativas principalmente do setor produtivo. No segundo, o escopo de tempo é maior e consequência do primeiro, levando a desdobramentos junto a cidade que abriga os EI.

A participação de autoridades federais, estaduais e locais foi tida como chave nos casos analisados. Destacam-se pelo lado federal a elaboração de políticas para a promoção da inovação que, embora enfatize questóes econômicas e o fortalecimento do setor industrial brasileiro, têm-se constituído em um dos principais fundamentos para a criação e indução dos EI no meio urbano. Pelo lado estadual e local, relevaram as participaçóes de autoridades, normalmente representadas por gestores e planejadores de desenvolvimento regional, na institucionalização dos EI, mais precisamente na governança dos EI, de acordo com papéis sugeridos pela abordagem de hélice-tripla. Finalmente, há expressiva participação das autoridades municipais, também normalmente representadas por gestores e planejadores de desenvolvimento urbano e regional, por meio do Plano Diretor. O Plano é um instrumento importante de gestấo urbana, instituído por força de lei no Brasil, parte do chamado Estatuto da Cidade, e que estabelece diretrizes para o desenvolvimento urbano em várias dimensóes.

\section{Agradecimientos}

A presente pesquisa só foi possível graças ao apoio financeiro e institucional da Coordenaçáo de Aperfeiçoamento de Pessoal de Nível Superior (CAPEs) do Ministério da Educação do Brasil, por intermédio do processo N. BEX 6555/I 4-4, Estágio Sênior.

\section{Referências bibliográficas}

Alvim, A. A. T. B. (2008). Novas configuraçôes produtivas como estratégias de desenvolvimento local: perspectivas ao planejamento urbano. Exacta (São Paulo), 6(1), 157-168.

Alvim, A. A. T. B., Castro, L. G. R. (2005). Arranjos Produtivos Locais e Recuperação de Áreas Urbanas: Os Casos de Porto Alegre e Recife, Brasil. XI Seminário de Arquitetura Latino Americana - SAL, México.

Arbix, G. (2007). Inovar ou inovar: A indístria brasileira entre o passado e o futuro. São Paulo, SP: Universidade de São Paulo (UsP).

Associação Nacional de Entidades Promotoras de Empreendimentos Inovadores (Anprotec). (2008). Prêmio nacional. Associação Nacional de Entidades Promotoras de Empreendimentos Inovadores. Em http//anprotec.org.br/site/premio-nacional/

Botha, A., Bussin, M., \& Swardt, L. D. (2011). An employer brand predictive model for talent attraction and retention. SA Journal of Human Resource Management, 9(1). Em http:// www.sajhrm.co.za/index.php/sajhrm/article/view/388/404 
Brown, T. \& Ulijn, J. (eds.). (2004). Innovation, entrepreneurship and culture. The interaction between technology, progress and economic growth. Northampton, MA: Edward Elgar Publishing. http://dx.doi.org/10.4337/9781845420550

Cai, Y. (2015). What contextual factors shape "innovation in innovation"? - Integration of insights of the Triple Helix and the institutional logics perspective. Social Science Information, 54(3), 299-326. http://dx.doi.org/10.1177/0539018415583527

Castells, M. (1996). The information age: Economy, society and culture (Vol. I). Cambridge, MA: Blackwell.

Castells, M. (1997). The power of identity: The information age: Economy, society, and culture (2nd ed., Vol. II). Cambridge, MA: Blackwell.

Castells, M. (1998). End of millennium, The information age: Economy, society and culture (Vol. III). Oxford: Blackwell.

Clarke, T. (2001). The knowledge economy. Education Training, 43(4/5), 189-196. http:// dx.doi.org/10.1108/00400910110399184.

Damião, D., Catharino, M. \& Zouain, D. (2006). Urban Technology Parks Model as instrument of Public Policies for regional/local development: Technology Park of Sao Paulo. XXII IASP - World Conference on Science and Technology Parks. Helsinki.

Davenport, T. H. (2005). Thinking for a living: how to get better performance and results from knowledge workers. Boston: Harvard Business School Press.

De Negri, J. A., Kubota, L. C. \& Baessa, A. R. (2008). Políticas de incentivo à inovação tecnológica no Brasil. Brasília, DF: Instituto de Pesquisa Econômica Aplicada (IPEA).

Drucker, P. F. (2011). The age of discontinuity; Guidelines to our changing society (9th printing). New York: Harper \& Row.

Duarte, F. (2005). Cidades inteligentes: Inovaçấo tecnológica no meio urbano. São Paulo em Perspectiva 19(1), 122-131. Em http://www.scielo.br/scielo.php?script=sci_ arttext\&pid=S0102-88392005000100011

Engel, J. S. (2014). Global clusters of innovation: entrepreneurial engines of economic growth around the world. Cheltenham, uк: Edward Elgar.

Etzkowitz, H. (2008). The triple helix. University-Industry-Government innovation in action. New York: Routledge. https://doi.org/10.4324/9780203929605.fmatt

Federação da Indústrias do Estado do Rio de Janeiro (FIRJAN). (2014). Mapeamento da Indústria Criativa no Brasil (No. 1). Rio de Janeiro. Retrieved from http://www.firjan.com.br/ economiacriativa/download/mapeamento-industria-criativa-2014.pdf

Florida, R. L. (2002). The rise of the creative class: And how it's transforming work, leisure, community and everyday life. New York: Basic Books.

Florida, R. L. (2005). Cities and the creative class. New York: Routledge.

Gibbons, M. (1994). The new production of knowledge: the dynamics of science and research in contemporary societies. London: SAGE Publications.

Gil, A. C. (1999). Métodos e técnicas de pesquisa social. São Paulo: Atlas.

Hearn, G. (2008). Knowledge economies and urban planning knowledge. Em T. Ygitcanlar \& K. Velibeyoglu \& S. Baum (eds.), Knowledge-based urban development: Planning and application in the information era (1st ed.), ebook ISBN-13: 978-1-59904-722-5, pp. xx-xxvi.

Hershey, PA: IGI Global (USA).

Hesmondhalgh, D. (2007). The cultural industries. Los Angeles: SAge. 
Howkins, J. (2013). The creative economy: How people make money from ideas (2nd ed.). London: Penguin.

Hwang, V. W. \& Horowitt, G. (2012). The rainforest: The secret to building the next Silicon Valley. Los Altos Hills, ca: Regenwald.

Knight, R. (1995). Knowledge-based development: Policy and planning implications for cities. Urban Studies, 32(2), 225-260. https://doi.org/10.1080/00420989550013068

Knight, R. (2008). Knowledge-based development: The challenge for cities. Em T. Ygitcanlar $\&$ K. Velibeyoglu \& S. Baum (eds.), Knowledge-based urban development: planning and application in the information era (1st ed.), ebook ISBN-13: 978-1-59904-722-5, pp. xiv-xix.

Hershey (PA): IGI Global (USA).

Leite, C. \& Awad, J. D. (2012). Cidades sustentáveis, cidades inteligentes: Desenvolvimento sustentável num planeta urbano. Porto Alegre, RS: Bookman.

Maldonado, A. M. \& Romein, A. (2010). The role of organisational capacity and knowledgebased development: The reinvention of Eindhoven. International Journal of KnowledgeBased Development, 1(1/2), 79. https://doi.org/10.1504/IJKBD.2010.032587

Malhotra, N. K. \& Taylor, R. B. (2008). Introdução à pesquisa de marketing (3rd ed.). São Paulo: Pearson Prentice Hall.

May, T. \& Perry, B. (2011a). Contours and conflicts in scale: Science, knowledge and urban development.LocalEconomy, 26(8),715-720.https://doi.org/10.1177/0269094211422192

May, T. \& Perry, B. (2011b). Urban research in the knowledge economy: Content, context and outlook.Built Environment, 37(3), 352-367.

Minayo, M. C., Assis, S. G. \& Souza, E. R. (2005). Avaliação por triangulação de métodos: Abordagem de programas sociais. Rio de Janeiro, RJ: Editora Fiocruz.

Ministério da Ciência, Tecnologia e Inovação (мСтI). (2014). Estudo de projetos de alta complexidade: Indicadores de Parques Tecnológicos (1st ed., Vol. 1, Ser. 1, Rep.). Brasilia, DF: MCTI. Em http://www.anprotec.org.br/Relata/PNI_FINAL_web.pdf

Moulaert, F., Nussbaumer,J. (2005). Beyond the learning region: the dialectics of innovation and culture in territorial development - Learning from Clusters, 2005 - Springer.

Nonaka, I. \& Konno, N. (1998). The concept of "Ba": Building a foundation for knowledge creation. California Management Review, 40(3), 40-54. https://doi. org/10.2307/41165942

Nonaka, I. \& Takeuchi, H. (1995). The knowledge-creating company: How Japanese companies create the dynamics of innovation. New York: Oxford University Press.

Organisation for Economic Co-operation and Development (OECD). (2010). The OECD innovation strategy: getting a head start on tomorrow. Paris: OECD.

Pacheco, C. A. \& De Almeida, J. G. (2013). A política de inovação. Texto para discussão, n. 219. Campinas, sp: Instituto de Economia da Unicamp.

Porter, M. (1990). The competitive advantage of nations. New York: Free Press.

Powell, W. W. \& Snellman, K. (2004). The knowledge economy. Annual Review of Sociology, 30(1), 199-220. https://doi.org/10.1146/annurev.soc.29.010202.100037

Pyöriä, P. (2005). The concept of knowledge work revisited. Journal of Knowledge Management, 9(3), 116-127. https://doi.org/10.1108/13673270510602818 
Rosenfeld, S. A. (1996). Does cooperation enhance competitiveness? Assessing the impacts of inter-firm collaboration. Research Policy, 25(2), 247-263. https://doi. org/10.1016/0048-7333(95)00835-7

Schlemm, M., Spinosa, L. M. \& Reis, R. (2015). Novos paradigmas para a política de inovação: Implicaçôes e inspiraçóes do ecossistema de inovação do Vale do Silício. Relatório Técnico Projeto NPIN/MCTI.

Seidl, P. R., Longo, W. P., Etzkowitz, H, \& Leydesdorff, L. (1999). Comments on the application of the Triple Helix of innovation to developing countries. Science and Public Policy, 26(2), 137-139. https://doi.org/10.3152/147154399781782527

Smith, K. (2000). Innovation as a systemic phenomenon: Rethinking the role of policy. Enterprise and Innovation Management Studies, 1(1), 73-102. http://dx.doi. org/10.1080/146324400363536

Spinosa, L. M. \& Krama, M. (2014). Ecossistema de inovação e meio urbano: Principais desafios para os seus gestores. Em V. S. Bagnato, W. R. Barrionuevo \& S. Perussi-Filho (eds.), Relevância Imobiliária Ambiental e Parques Tecnológicos (pp. 65-89). São Paulo: Universidades de São Paulo (UsP)

Spinosa, L. M. \& Moura, E. (2013). Uma abordagem e uma ferramenta orientadas weB para avaliação da percepção de eficácia de parques tecnológicos. 30ª Conferência Mundial da IASP e 230 Seminário Anprotec. Recife. https://doi.org/10.13140/RG.2.1.4558.9367

Spinosa,L. M., Reis, R. \& Schlemm, M. (2016). A process-based approach to support entrepreneurship and innovation ecosystem management - A Brazilian trial (4 Vols.). https://doi.org/10.1142/9789813220621_0012

Van Wezemael, J. E. (2008). Knowledge creation in urban and knowledge environment. Em T. Yigitcanlar, K. Velibeyoglu \& S. Baum, Knowledge-based urban development: Planning and applications in the information era (pp. 1-20). Hershey, PA: IGI Global (USA). https://doi.org/10.4018/978-1-59904-720-1.ch001)

World Bank (2010). Innovation policy: A guide for developing countries. Washington, D.c.: World Bank. Em http://hdl.handle.net/10986/2460

Yigitcanlar, T. (2010). Rethinking sustainable development: Urban management, engineering, and design. Hershey, pa: Engineering Science Reference.

Yigitcanlar, T. (2011). Making space and place for the knowledge economy: Knowledge-based development of Australian cities. European Planning Studies, 18(11), 1769-1786. http://dx.doi.org/10.1080/09654313.2010.512163

Yigitcanlar, T., Velibeyoglu, K. \& Baum, S. (2008). Preface of Knowledge-Based Urban Development: Planning and application in the information era (pp. xxvii-xxxii), Hershey (pA): IGI Global (USA). 